\section{Genotyping of the Helicobacter pylori isolates of raw milk and traditional dairy products}

\author{
Leila Khaji, ${ }^{1}$ Gholamreza Banisharif, ${ }^{2}$ \\ Iman Alavi \\ ${ }^{1}$ Department of Veterinary Medicine, \\ Faculty of Veterinary Medicine, \\ University of Tehran; ${ }^{2}$ Department of \\ Microbiology, Faculty of Basic Sciences, \\ Shahrekord Branch, Islamic Azad \\ University, Shahrekord, Iran
}

\begin{abstract}
Notwithstanding the substantial clinical impact of Helicobacter pylori, its convinced routes of transmission and sources have not been reported. Based on the quarrelsome hypothesis, foods and especially dairy products play an authoritative role in the transmission of $H$. pylori to humans. The current investigation was done to study the prevalence rate and distribution of vacA genotypes in the $H$. pylori strains isolated from the raw milk and traditional dairy products. Three-hundred milk and dairy samples were collected and directly transported to laboratory. Samples were cultured and $H$. pylori isolates were approved using the 16s rRNAbased PCR amplification. Positive strains were tested for distribution of vacA genotypes using the multiplex-PCR. Sixty out of 300 samples (20\%) harbored H. pylori. Prevalence of $H$. pylori in milk and traditional dairy products were $38.75 \%$ and $13.18 \%$, respectively. Ovine milk (45\%) and traditional cheese (40\%) had the highest prevalence of $H$. pylori. VacAsla (91.66\%), vacAmla (61.61\%) vacAs2 $(36.66 \%)$ and vacAm2 $(31.66 \%)$ were the most commonly detected genotypes. Ovine milk and traditional cheese had the most diverse genotypes. Slamla (41.66\%), $s 2 m 1 a(25 \%)$, slam2 (16.66\%) and $s 2 m 2$ $(13.33 \%)$ were the most commonly detected combined genotypes. Raw milk and traditional dairy products are latent sources of $H$. pylori. Similarity in the genotyping pattern of $H$. pylori strains of various samples represents their similar sources of infection. Further studies are required to found the exact sources of $H$. pylori strains in raw milk and traditional dairy products.
\end{abstract}

\section{Introduction}

The contamination of food with microbes can happen at any step of the food chain. Milk is virtually sterile when it is synthesized in a healthy animal's udder. Ruminants are natural reservoirs of bacteria. Many of these bacteria are not harmful to humans, but some may be harmful to humans even though the animals are not affected and appear healthy. The extremely nourishing nature of dairy products makes them particularly suitable media for bacterial proliferation. Raw milk and dairy products can harbor a variety of pathogenic organisms. ${ }^{1}$

Though Helicobacter pylori (H. pylori) have been considered as a main cause of mucosa associated lymphoma, peptic ulcer disease, type B gastritis, and gastric adenocarcinoma, roles of foods and especially dairy products in its transmission are still unknown. ${ }^{2-4} H$. pylori was found in stomach of domestic animals in the absence of associated gastritis, it was recovery from milk, meat and gastric tissue of domestic ruminants suggest that domestic animals and their milk may be reservoirs of $H$. pylori. ${ }^{2-4}$ Suitable circumstances for growth and survival of $H$. pylori in milk and dairy products provide adequate settings for transmission of H. pylori from these foodstuffs to human. ${ }^{5}$

The severity of clinical complications caused by $H$. pylori is depends on several factors. Presence of pathogenic virulence genes and genotypes the most important factor responsible for $H$. pylori infections. Vacuolating cytotoxin (vacA) is one of the most important virulence factors in the occurrence of human clinical diseases caused by this bacterium. The vacA belongs to the group of genes with variable genotypes or structures. The vacA gene is present in virtually all strains of $H$. pylori but it is polymorphic, comprising variable signal regions (type $s 1$ or $s 2$ ) and mid-regions (type $m 1$ or $m 2$ ). The $s 1$ type is additional subtyped into $s l a, s l b$ and $s l c$ subtypes, and the $m l$ into $m l a$ and $m l b$ subtypes. 6,7 The mosaic combination of $\mathrm{s}$ and m-region allelic types determines the particular cytotoxin and, consequently, the pathogenicity of the bacterium. Genotyping using vacA virulence marker is considered as one of the best approaches for study of correlations between $H$. pylori isolates from different samples. ${ }^{6,7}$

\section{Materials and Methods}

\section{Sample collection}

From May 2015 to July 2015, overall 300 dairy products including raw bovine milk $(n=40)$, raw ovine milk $(n=40)$, traditional cheese $(n=50)$, traditional cream $(n=50)$, traditional butter $(n=60)$ and tradi-
Correspondence: Leila Khaji, Doctor Veterinary Medicine, Faculty of Veterinary Medicine, University of Tehran, Tehran, Iran. Tel.: +98.9125.252383.

E-mail: L.kh52834@yahoo.com

Key words: Helicobacter pylori, Prevalence, Genotyping, Raw milk, Traditional dairy.

Acknowledgements: the authors would like to thank from Prof. Ebrahim Rahimi at the Department of Food Hygiene and Quality Control, Faculty of Veterinary Medicine, Shahrekord Branch, Islamic Azad University, Shahrekord, Iran for his significant technical provision.

Contributions: the authors contributed equally.

Conflict of interest: the authors declare no potential conflict of interest.

Received for publication: 29 June 2017.

Revision received: 9 August 2017.

Accepted for publication: 19 August 2017.

This work is licensed under a Creative Commons Attribution NonCommercial 4.0 License (CC BY-NC 4.0).

(C) Copyright L. Khaji et al., 2017

Licensee PAGEPress, Italy

Microbiology Research 2017; 8:7288

doi:10.4081/mr.2017.7288

tional ice-cream $(n=60)$ were purchased from the supermarkets of Tehran province, Iran. Samples (100 mL, in sterile glass containers) were transported to the laboratory at $4^{\circ} \mathrm{C}$. All samples were kept under refrigeration in plastic bags; information about dates of production and of assigned shelf lives was not presented.

\section{Isolation of Helicobacter pylori}

Twenty five milliliters of each homogenized sample were added to $225 \mathrm{~mL}$ of Wilkins Chalgren anaerobe broth (Oxoid, UK) supplemented with colistin methanesulfonate $(30 \mathrm{mg} / \mathrm{L})$ and $5 \%$ of horse serum (Sigma, St. Louis, MO, USA) and nalidixic acid $(30 \mathrm{mg} / \mathrm{L})$, vancomycin $(10 \mathrm{mg} / \mathrm{L})$ cycloheximide $(100 \mathrm{mg} / \mathrm{L})$ and trimethoprim $(30 \mathrm{mg} / \mathrm{L})($ Sigma, USA) and incubated for 7 days at $37^{\circ} \mathrm{C}$ with shaking under microaerophilic conditions. Then, $0.1 \mathrm{~mL}$ of the enrichment selective broth was plated onto Wilkins Chalgren anaerobe agar (Oxoid, UK) supplemented with 5\% of defibrinated horse blood and $30 \mathrm{mg} / \mathrm{L}$ colistin methanesulfonate, $100 \mathrm{mg} / \mathrm{L}$ cycloheximide, $30 \mathrm{mg} / \mathrm{L}$ nalidixic acid, $30 \mathrm{mg} / \mathrm{L}$ trimethoprim, and $10 \mathrm{mg} / \mathrm{L}$ vancomycin (Sigma, USA) and incubated for 7 days at $37^{\circ} \mathrm{C}$ under microaerophilic conditions. For 
comparison, a reference strain of $H$. pylori (ATCC 43504) was employed.

\section{DNA extraction and Helicobacter pylori 16S rRNA gene amplification}

Suspected colonies were identified as H. pylori based on the PCR technique. Genomic DNA was extracted from the colonies with typical characters of $H$. pylori using a DNA extraction kit for cells and tissues (Roche Applied Science, Germany, 11814770001 ) according to the manufacturer's instructions and its density was assessed by optic densitometry. Extracted DNA was amplified for the $16 \mathrm{~S} r R N A$ gene (primers: HP-F: 5'-CTGGAGAGACTAAGCCCTCC-3' and HP-R: 5'-ATTACTGACGCTGATTGTGC-3') (110 bp). ${ }^{8}$ PCR reactions were performed in a final volume of $50 \mu \mathrm{L}$ containing $5 \mu \mathrm{L} 10 \times$ buffer + $\mathrm{MgCl}_{2}, 2 \mathrm{mM}$ dNTP, 2 unit Taq DNA polymerase, $100 \mathrm{ng}$ genomic DNA as a template, and 25 picomole of each primer. PCR was performed using a thermal cycler (Eppendorf Co., Germany) under the following conditions: an initial denaturation for 2 minutes at $94^{\circ} \mathrm{C} ; 30$ cycles of $95^{\circ} \mathrm{C}$ for $30 \mathrm{~s}, 60^{\circ} \mathrm{C}$ for $30 \mathrm{~s}$, and $72^{\circ} \mathrm{C}$ for $30 \mathrm{~s}$ and a final extension at $72^{\circ} \mathrm{C}$ for $8 \mathrm{~min}$.

\section{Genotyping of vacA genes of Helicobacter pylori}

Presence of the vacA ( $11 a, s 1 b, s 1 c, m 1 a$, $m 1 b$ and $m 2$ ) alleles were determined using PCR technique. Primers, PCR conditions and volume of each reaction are shown in Table 1. ${ }^{9}$ PCR amplifications were performed using a DNA thermal cycler (Eppendorf Co., Germany). All runs included one negative DNA control consisting of PCR grade water and two or more positive controls (26695, J99, SS1, Tx30, 88-23 and 84-183).

\section{Gel electrophoresis}

The PCR amplification products (10 $\mu \mathrm{L})$ were subjected to electrophoresis in a $1.5 \%$ agarose gel in $1 \mathrm{X}$ TBE buffer at $80 \mathrm{~V}$ for $30 \mathrm{~min}$, stained with ethidium bromide, and images were obtained in a UVIdoc gel documentation systems (UK). The PCR products were identified by 100 bp DNA size marker (Fermentas, Germany).

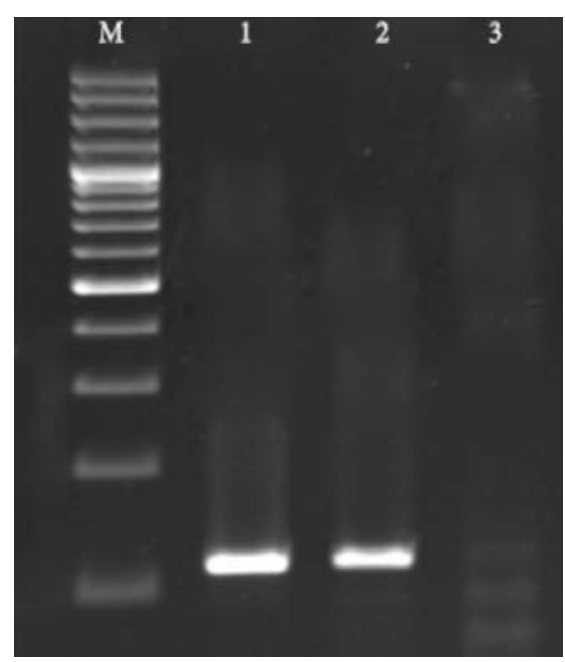

Figure 1. Results of the gel electrophoresis for the $16 S r R N A$ gene of the $H$. pylori strains isolated from dairy products. $M$ : 100 bp ladder, 1: Positive sample for the 16SrRNA gene (110 bp), 2: Positive control (H. pylori ATCC 43504) and 3: Negative control (PCR grade water (Fermetas, Germany)).

Table 1. Oligonucleotide primers and PCR conditions used for genotyping of Helicobacter pylori strains isolated from dairy products. ${ }^{9}$

\begin{tabular}{|c|c|c|c|c|}
\hline Genes & Primer Sequence $\left(5^{\prime}-3^{\prime}\right)$ & Size of product (bp) & Volume of PCR reaction (50 $\mathrm{LL})$ & PCR programs \\
\hline \multirow[t]{2}{*}{ vacA sla } & F: CTCTCGCTTTAGTAGGAGC & 213 & $5 \mu \mathrm{L}$ PCR buffer 10X (Fermentas) & 1 cycle: \\
\hline & R: CTGCTTGAATGCGCCAAAC & & $1.5 \mathrm{mM} \mathrm{Mgcl}_{2}$ & $95^{0 \mathrm{C}}$-.------- $1 \mathrm{~min}$. \\
\hline \multirow[t]{2}{*}{ vacA slb } & F: AGCGCCATACCGCAAGAG & 187 & $200 \mu \mathrm{M}$ dNTP (Fermentas) & 32 cycle: \\
\hline & CTGCTTGAATGCGCCAAAC & & $0.5 \mu \mathrm{M}$ of each primers $\mathrm{F} \& \mathrm{R}$ & 95 OC \\
\hline \multirow[t]{2}{*}{ vacA slc } & F: CTCTCGCTTTAGTGGGGYT & 213 & 1.25 U Taq DNA polymerase (Fermentas) & $640 \mathrm{CC}$ \\
\hline & R: CTGCTTGAATGCGCCAAAC & & $2.5 \mu \mathrm{L}$ DNA template & $72^{0 \mathrm{C}}$ \\
\hline \multirow[t]{2}{*}{ vacA s2 } & F: GCTAACACGCCAAATGATCC & & & 1 cycle: \\
\hline & $\begin{array}{l}\text { R: CTGCTTGAATGCGCCAAAC } \\
\text { F: GGTCAAAATGCGGTCATGG }\end{array}$ & 199 & & $72^{\text {oC }}$----------- 5 min \\
\hline vacA mlA & R: CCATTGGTACCTGTAGAAAC & 290 & & \\
\hline \multirow[t]{2}{*}{ vacA mlB } & F: GGCCCCAATGCAGTCATGGA & & & \\
\hline & R: GCTGTTAGTGCCTAAAGAAGCAT & 291 & & \\
\hline \multirow[t]{2}{*}{ vacA m $m_{2}$} & F: GGAGCCCCAGGAAACATTG & & & \\
\hline & R: CATAACTAGCGCCTTGCA & 352 & & \\
\hline
\end{tabular}

Table 2. Prevalence of Helicobacter pylori in various dairy products.

\begin{tabular}{|c|c|c|c|}
\hline Samples & No. samples collected & No. positive samples for $\boldsymbol{H}$. pylori (\%) & PCR confirmation (\%) \\
\hline \multicolumn{4}{|l|}{ Raw milk } \\
\hline Bovine & 40 & $13(32.50)$ & $13(32.50)$ \\
\hline Ovine & 40 & $18(45)$ & $18(45)$ \\
\hline Total & 80 & $31(38.75)$ & $31(38.75)$ \\
\hline \multicolumn{4}{|c|}{ Traditional dairy products } \\
\hline Cheese & 50 & $20(40)$ & $20(40)$ \\
\hline Cream & 50 & $2(4)$ & $2(4)$ \\
\hline Butter & 60 & $2(3.33)$ & $2(3.33)$ \\
\hline Ice-cream & 60 & $5(8.33)$ & $5(8.33)$ \\
\hline Total & 220 & $29(13.18)$ & $29(13.18)$ \\
\hline Total & 300 & $60(20)$ & $60(20)$ \\
\hline
\end{tabular}




\section{Statistical analysis}

Data were transferred to Microsoft Excel spreadsheet (Microsoft Corp., Redmond, WA, USA) for analysis. Using SPSS 16.0 statistical software (SPSS Inc., Chicago, IL, USA), Chi-square test and Fisher's exact two-tailed test analysis was performed and differences were considered significant at values of $\mathrm{P}<0.05$. Distribution of $H$. pylori genotypes isolated from dairy products were statistically analyzed.

\section{Results}

Table 2 represents the total prevalence of $H$. pylori isolated from different types of dairy products. All of the $H$. pylori isolates harbored the 16SrRNA gene in the PCR amplification (Figure 1). We found that 60 out of 300 samples $(20 \%)$ were positive for the H. pylori. Prevalence of $H$. pylori among milk and traditional dairy products were $38.75 \%$ and $13.18 \%$, respectively. Ovine milk $(45 \%)$ and traditional cheese (40\%) had the highest prevalence of $H$. pylori strains. Statistically significant differences were seen between the type of samples and prevalence of $H$. pylori strains $(\mathrm{P}<0.05)$.

Table 3 represents the distribution of vacA genotypes among $H$. pylori isolates of dairy products. VacAsla $(91.66 \%), \mathrm{mla}$ (61.61\%) s2 (36.66\%) and $m 2$ (31.66\%) were the most commonly detected genotypes amongst the $H$. pylori isolates. Ovine milk and traditional cheese had the most diverse genotypes. VacAs1c (5\%) had the lowest prevalence amongst the $H$. pylori isolates of all dairy samples. Statistically significant differences were seen between the type of samples and prevalence of different genotypes $(\mathrm{P}<0.05)$.

Table 4 represents the distribution of combined genotypes of the $H$. pylori strains isolated from all studied samples. We found that slamla (41.66\%), s2mla (25\%), slam $2(16.66 \%)$ and $s 2 m 2(13.33 \%)$ were the most commonly detected genotypes among the H. pylori isolates of all dairy products. There were no positive results for $s 1 \mathrm{~cm} 1 \mathrm{~b}$ and $s 1 \mathrm{~cm} 2$ combined genotypes.

\section{Discussion}

Results of the present study revealed that $20 \%$ of dairy products were contaminated with $H$. pylori strains which showed an important public health threat regarding the consumption of raw milk and traditional dairy products. Results also indicated the high distribution of putative genotypes in the H. pylori isolates of milk and dairy products.

Prevalence of $H$. pylori in dairy products of our study $(20 \%)$ was higher than that of Rahimi and Kheirabadi (2012) ${ }^{10}$ (Iran, $0.67 \%$ in milk samples), Gilani et al. $(2017)^{11}$ (Iran, 5\% in meat samples) and Atapoor et al. $(2014)^{12}(9.56 \%$ in vegetable), Talaei et al. $(2015)^{13}$ (Iran, 4.76$20 \%$ in milk samples), Ghasemian Safaei et al. $(2011)^{14}$ (Iran, 16\% in milk samples), Esmaeiligoudarzi et al. (2015) ${ }^{15}$ (Iran, $13.75 \%$ in milk samples and dairy products), Mousavi et al. (2014) ${ }^{16}$ (Iran, $19.80 \%$ in milk samples and $19.20 \%$ in dairy products) and Yahaghi et al. (2014) ${ }^{9}$ (Iran, $14 \%$ in salad and $13.68 \%$ in vegetable), while was lower than that of Fujimura et al. (2002) $)^{17}$ (Japan, $72.20 \%$ in milk samples), El-Gohary et al. (2015) ${ }^{18}$ (Egypt, $21.70 \%$ in milk samples), Saeidi and Sheikhshahrokh (2016) ${ }^{19}$ (Iran, 21.90\% in milk and $26.25 \%$ in meat samples). Ghorbani et al. $(2016)^{20}$ reported that the prevalence of $H$. pylori in food items were $20 \%$. They showed that vegetable sandwich (45\%), minced meat (32\%) and meat sandwich $(20 \%)$ were the most commonly contaminated samples.

Our results showed that ovine milk samples had the highest prevalence of $H$. pylori. This substance has been accepted by other researchers. ${ }^{10,11,13,16,19}$ It is maybe due to the high ability of the sheep stomach to keep H. pylori and then its transmission into the environment. The main reason for the high prevalence of $H$. pylori in dairy samples is the fact that milk has an appropriate conditions and especially $\mathrm{pH}$ and activated water (AW) which support the growth and survival of $H$. pylori strains. Traditional cheese had also high prevalence of $H$. pylori and it is maybe due to the fact that the milk which used for preparation of cheese should not heat higher than $40^{\circ} \mathrm{C}$. Therefore, $H$. pylori and also other types of bacteria can survive in this type of traditional dairy.

VacAsla, mla, s2 and $m 2$ genotypes had a considerable prevalence in $H$. pylori strains. Similar findings have been reported previously in milk, ${ }^{10,16,19}$ meat,,${ }^{9,11,16}$ vegetable $^{9}$ and ready to eat foods. ${ }^{20}$ Hemmatinezhad et al. $(2016)^{21}$ reported that the prevalence of $H$. pylori in various types of ready to eat food samples were $13.45 \%$. They showed that olvie salad $(36 \%)$, restaurant salad $(30 \%)$, fruit salad $(28 \%)$ and soup $(22 \%)$ had the highest prevalence rate. Their findings reported that the most commonly detected combined genotypes were slam2 (70.27\%), slamla (39.18\%) and mlam 2 (31.08\%) which was similar to our findings. Yahaghi et al. $(2014)^{9}$ revealed that cagA $(57.62 \%)$, vacA sla $(37.28 \%)$ and vacA mla $(30.50 \%)$ had the highest prevalence among the $H$. pylori strains of vegetables. High prevalence of $v a c A$ genotypes among the clinical isolates and cases of gastrointestinal disorders have been reported from Iran, ${ }^{22}$ United States, ${ }^{23}$ Australia, ${ }^{24}$ United Kingdom ${ }^{25}$ and China. ${ }^{26}$ Adjacent connotation of vacA genotypes with production of interleukin 8 (IL-8) and cytotoxins, adhesion to gastric epithelial cells, occurrence of inflammation, vacuolization, necrosis and apoptosis of epithelial cells has been reported in previously published data. ${ }^{27,28}$ High prevalence of these genotypes in milk and dairy samples of our investigation showed their high pathogenic nature.

Table 3. Distribution of $v a c A$ genotypes among the Helicobacter pylori strains of dairy products.

\begin{tabular}{|c|c|c|c|c|c|c|c|}
\hline \multirow[t]{2}{*}{ Samples (n. positive) } & \multicolumn{7}{|c|}{ Distribution of vacA genotypes (\%) } \\
\hline & S1a & S1b & S1c & S2 & M1a & M1b & M2 \\
\hline Bovine milk (13) & $10(76.92)$ & $2(15.38)$ & - & $5(38.46)$ & $8(61.53)$ & $3(23.07)$ & $5(38.46)$ \\
\hline Ovine milk (18) & $18(100)$ & $3(16.66)$ & $1(5.55)$ & $6(33.33)$ & $10(55.55)$ & $3(16.66)$ & $4(22.22)$ \\
\hline Traditional cheese (20) & $19(95)$ & $5(25)$ & $2(10)$ & $7(35)$ & $13(65)$ & $4(20)$ & $6(30)$ \\
\hline Traditional cream (2) & $2(100)$ & - & - & $1(50)$ & $2(100)$ & - & $1(50)$ \\
\hline Traditional butter (2) & $2(100)$ & - & - & $1(50)$ & $1(50)$ & - & $1(50)$ \\
\hline Traditional ice-cream (5) & $4(80)$ & $1(20)$ & - & $2(40)$ & $3(60)$ & $1(20)$ & $2(40)$ \\
\hline Total (60) & $55(91.66)$ & $11(18.33)$ & $3(5)$ & $22(36.66)$ & $37(61.66)$ & $11(18.33)$ & $19(31.66)$ \\
\hline
\end{tabular}


Table 4. Distribution of various combined alleles of the vacA genotypes of Helicobacter pylori isolated from dairy products.

\begin{tabular}{lc} 
Genotypes & Prevalence $(\%)^{*}$ \\
S1am1a & $25(41.66)$ \\
S1am1b & $7(11.66)$ \\
\hline S1am2 & $10(16.66)$ \\
S1bm1a & $4(6.66)$ \\
S1bm1b & $2(3.33)$ \\
S1bm2 & $3(5)$ \\
S1cm1a & $1(1.66)$ \\
S1cm1b & - \\
S1cm2 & - \\
S2m1a & $15(25)$ \\
S2m1b & $6(10)$ \\
S2m2 & $8(13.33)$ \\
\hline
\end{tabular}

*From a total of $60 \mathrm{H}$. pylori isolates.

\section{Conclusions}

Iranian raw milk and traditional dairy products harbor H. pylori strains with considerable distribution of vacA genotypes. Significant occurrence of $H$. pylori suggests that contaminated milk maybe the sources of H. pylori and their pathogenic genotypes. Similarity in the genotype pattern of $H$. pylori strains of various samples for the $v a c A$ alleles signifies their similar sources of infection. Simultaneous presence of these genotypes together in some of our strains showed their high pathogenicity. Regarding the high prevalence rate of pathogenic $H$. pylori beside the high consumption rate of milk and dairy products in Iran, serious public health hazard faced to the consumers.

\section{References}

1. Momtaz H, Farzan R, Rahimi E, et al. Molecular characterization of Shiga toxin-producing Escherichia coli isolated from ruminant and donkey raw milk samples and traditional dairy products in Iran. Sci World J 2012;2012:231342.

2. Dixit MD, Bhat KG, Dayal A. Role of Helicobacter pylori specific heat shock protein-60 antibodies in the aetiology of coronary artery disease. Microbiol Res 2012;3.

3. Sambashivaiah S, Bilichodmath S, Nanjaiah N, et al. Helicobacter Pylori in periodontal pockets of chronic periodontitis patients with and without type II diabetes mellitus: a randomized controlled trial. Microbiol Res 2011;2.

4. Herrera AG. Helicobacter pylori and food products: a public health problem.
Methods Mol Biol 2004;268:297-301.

5. Vale FF, Vítor JM. Transmission pathway of Helicobacter pylori: does food play a role in rural and urban areas. Int J Food Microbiol 2010;138:1-12.

6. Román-Román A, Martínez-Carrillo $\mathrm{DN}$, Atrisco-Morales J, et al. Helicobacter pylori vacA s1m1 genotype but not cagA or babA2 increase the risk of ulcer and gastric cancer in patients from Southern Mexico. Gut Pathog 2017;9:18.

7. Pinto-Ribeiro I, Ferreira RM, Batalha S, et al. Helicobacter pylori vacA Genotypes in Chronic Gastritis and Gastric Carcinoma Patients from Macau, China. Toxins (Basel) 2016;8:142

8. Ho SA, Hoyle JA, Lewis FA. Direct polymerase chain reaction test for detection of Helicobacter pylori in humans and animals. J Clin Microbiol 1991;29:2543-2549.

9. Yahaghi E, Khamesipour F, Mashayekhi F, et al. Helicobacter pylori in vegetables and salads: genotyping and antimicrobial resistance properties. Biomed Res Int 2014;2014:757941.

10. Rahimi E, Kheirabadi EK. Detection of Helicobacter pylori in bovine, buffalo, camel, ovine, and caprine milk in Iran. Foodborne Pathog Dis 2012;9:453-6.

11. Gilani A, Razavilar V, Rokni N, et al. VacA and cagA genotypes of Helicobacter pylori isolated from raw meat in Isfahan province, Iran. Vet Res Forum 2017;8:75-80.

12. Atapoor S, Dehkordi FS, Rahimi E. Detection of Helicobacter pylori in various types of vegetables and salads. Jundishapur J Microbiol 2014;7: e10013.

13. Talaei R, Souod N, Momtaz H, et al. Milk of livestock as a possible transmission route of Helicobacter pylori infection. Gastroenterol Hepatol 2015;8:S30.

14. Safaei HG, Rahimi E, Zandi A, et al. Helicobacter pylori as a zoonotic infection: the detection of $\mathrm{H}$. pylori antigens in the milk and faeces of cows. J Res Med Sci 2011;16.184-7.

15. Esmaeiligoudarzi D, Tameshkel FS, Ajdarkosh H, et al. Prevalence of Helicobacter pyloriinIranian milk and dairy products using culture and ureC based-PCR techniques. Biomed Pharmacol J 2015;8:179-83.

16. Mousavi S, Safarpoor Dehkordi F, Rahimi E. Virulence factors and antibiotic resistance of Helicobacter pylori isolated from raw milk and unpasteurized dairy products in Iran. J Venom Anim Toxins Incl Trop Dis 2014;20:51. 17. Fujimura S, Kawamura T, Kato S, et al.
Detection of Helicobacter pylori in cow's milk. Let Appl Microbiol 2002;35:504-7.

18. El-Gohary AH, Yousef MA, Mohamed AA, et al. Epidemiological Study on $\mathrm{H}$. pylori in Cattle and Its Milk with Special Reference to its Zoonotic Importance. Biol Med 2015;7:1.

19. Saeidi E, Sheikhshahrokh A. VacA Genotype Status of Helicobacter pylori Isolated from Foods with Animal Origin. BioMed Res Int 2016;2016:1-6.

20. Ghorbani F, Gheisari E, Dehkordi FS. Genotyping of vacA alleles of Helicobacter pylori strains recovered from some Iranian food items. Trop J Pharm Res 2016;15:1631-6.

21. Hemmatinezhad B, Momtaz H, Rahimi E. VacA, cagA, iceA and oipA genotypes status and antimicrobial resistance properties of Helicobacter pylori isolated from various types of ready to eat foods. Ann Clinical Microbiol Antimicrob 2016;15:2.

22. Jafari F, Shokrzadeh L, Dabiri H, et al. VacA genotypes of Helicobacter pylori in relation to cagA status and clinical outcomes in Iranian populations. JPN J Infect Dis 2008;61:290.

23. Sicinschi LA, Correa P, Bravo LE, et al. Non-invasive Genotyping of Helicobacter pylori cagA, vacA, and hopQ from Asymptomatic Children. Helicobacter 2012;17:96-106.

24. Lu W, Wise MJ, Tay CY, et al. Comparative analysis of the full genome of Helicobacter pylori isolate Sahul64 identifies genes of high divergence. J Bacteriol 2014;196:1073-83.

25. Memon AA, Hussein NR, Deyi VYM, et al. Vacuolating cytotoxin genotypes are strong markers of gastric cancer and duodenal ulcer-associated Helicobacter pylori strains: a matched case-control study. J Clin Microbiol 2014;52:2984-9.

26. Wei GC, Chen J, Liu AY, et al. Prevalence of Helicobacter pylori vacA, cagA and iceA genotypes and correlation with clinical outcome. Exp Ther Med 2012;4:1039-44.

27. Siddique I, Al-Qabandi A, Al-Ali J, et al. Association between Helicobacter pylori genotypes and severity of chronic gastritis, peptic ulcer disease and gastric mucosal interleukin-8 levels: Evidence from a study in the Middle East. Gut Pathog 2014;6:41.

28. Yamaoka Y, Reddy R, Graham DY. Helicobacter pylori virulence factor genotypes in children in the United States: clues about genotype and outcome relationships. J Clin Microbiol 2010;48:2550-1 